УДК 512.536

Десятерик О. О.

м.н.с., відділ нейромережевих технологій обробки інформації, Міжнародний науково-навчальний центр інформаційних технологій та систем НАН України та МОН України (дисертація: механіко-математичний факультет, Київський Національний Університет імені Тараса Шевченка)

\title{
УМОВИ, ЗА ЯКИХ НАПІВГРУПА БРАНДТА НЕІЗОМОРФНА BAPIAHTY
}

У цій статті ми досліджуємо запитання чи є напівгрупа Брандта варіантом іншої напівгрупи. Ми довели, що варіант напівгрупи, яка не містить біциклічної піднапівгрупи не $\epsilon$ напівгрупою Брандта. Для нескінченної напівгрупи, яка містить біциклічну піднапівгрупу, варіант породжений елементом з цієї піднапівгрупи не є напівгрупою Брандта.

Ключові слова: напівгрупа Брандта, варіант, сандвіч напівгрупа, бічиклічна наniвгрупа.

\section{Вступ}

Вперше поняття варіанта було введено Ляпіним у [1], де він досліджував напівгрупу перетворень. Далі варіанти інших типів напівгруп досліджувалися різними авторами, наприклад у роботах [2-8] та розділі 13 монографії [9]і посилання до розділу.

У багатьох роботах розглядається ситуація, коли одна напівгрупа є варіантом іншої. Але залишається запитання, чи є такі напівгрупи, які не є варіантами інших.

У даній статті досліджено чи може напівгрупа Брандта бути варіантом, тобто бути ізоморфною варіанту деякої напівгрупи.

Ми довели, що варіант цілком 0-простої напівгрупи не є напівгрупою Брандта, тоді, зокрема, варіант жодної скінченної напівгрупи не $є$ напівгрупою Брандта. Для нескінченних напівгруп, які містять біциклічну піднапівгрупу доведено, що варіант породжений елементом з біциклічної піднапівгрупи не є напівгрупою Брандта.

Не доведеним залишається наступний випадок. Якщо напівгрупа містить біциклічну піднапівгрупу і варіант породжений елементом не з біциклічної піднапівгрупи.

\section{Необхідні означення та твердження}

Нехай $S$ напівгрупа і $a \in S$. Бінарна операція $*_{a}$ визначена на множині $S$ наступним чином $x *_{a} y=x a y$, де $x, y \in S \in$ асоціативною. Ця операція $*_{a}$ називається сандвіч множенням а напівгрупа $\left(S, *_{a}\right)$ називається варіантом або сандвіч напівгрупою.

Напівгрупою Брандта називається напівгрупа $S$ з нулем, яка задовольняє наступним аксіомам:

$(A 1)$ Якщо $a, b, c$ - такі елементи напівгрупи $S$, що $a c=b c \neq 0$ або $a c=c b \neq 0$, то $a=b$.

$(A 2)$ Якщо $a, b, c$ - такі елементи напівгрупи $S$, що $a b \neq 0$ i $b c \neq 0$, то $a b c \neq 0$.

$(A 3)$ Кожному елементу $a \neq 0$ напівгрупи $S$ відповідають: такий єдиний елемент $e \in S$, що $е a=a$; такий єдиний елемент $f \in S$ що $a f=a$; такий єдиний елемент $a^{\prime} \in S$, що $a^{\prime} a=f$.

$(A 4)$ Якщо $e$ та $f$ - ненульові ідемпотенти напівгрупи $S$, то $e S f \neq 0$. 
Напівгрупа $S$ називається регулярною, якщо для довільного $a \in S$ існує такий $x \in S$, що $a x a=a$.

Напівгрупа $S$ називається простою, якщо вона не містить власних (двосторонніх) ідеалів. Ідемпотент $f$ напівгрупи $S$ називається примітивним, якщо $f \neq 0$ і якщо 3 $e \leqslant f$ випливає, що $e=0$ або $e=f$. Цілком простою [0-простою] напівгрупою називається проста [0-проста] напівгрупа, яка містить примітивний ідемпотент.

Напівгрупа $\left\langle b^{l} a^{t} \mid a b=1\right\rangle$ породжена елементами $a$ та $b$, називається біциклічною $\mathrm{i}$ позначається $\mathfrak{B i}$.

Теорема 1. [10, теорема 3.9] Наступні три умови для напівгрупи $S$ з нулем еквівалентні:

(i) S- напівгрупа Брандта;

(ii) $S$ - чілком 0-проста інверсна напівгрупа;

(iii) $S$ ізоморфна (регулярній) рісівсъкій напівгрупі матричного типу $\mathcal{M}^{0}(G ; I, J ; \triangle)$ з одиничною сендвіч-матрищею $\triangle$ над групою з нулем $G^{0}$.

Твердження 1. [3] Нехай $\left(S, *_{a}\right)$ е 0-простою, тодi $S$ е 0-простою.

Твердження 2. [11] Кожна скінченна 0-проста напівгрупа е иілком 0-простою.

Твердження 3. [12, Proposition 3.2.1] 0-проста напівгрупа є иілком 0-простою тодi $i$ тільки тоді, коли вона не містить бічиклічної напівгрупи.

Теорема 2. [12, Теорема Pica $]$ Напівгрупа иілком 0-проста тоді $і$ тільки тоді, коли вона ізоморфна регулярній рісівсъкій напівгрупі матричного типу над групою з нулем.

\section{Напівгрупа Брандта}

Нехай $\left(S, *_{a}\right)$ - варіант напівгрупи $S$ з нулем, породжений елементом $a \in S$.

Твердження 4. Нехай варіант $\left(S, *_{a}\right)$ ізоморфний напівгрупі Брандта. Тоді напівгрупа $S$ e 0-простою.

Доведення. Оскільки $\left(S, *_{a}\right)$ ізоморфний напівгрупі Брандта, то з теореми 1. випливає, що $\left(S, *_{a}\right)$ є цілком 0-простою інверсною напівгрупою. Тоді за твердженням 1 . напівгрупа $S$ є 0-простою.

Твердження 5. Якщо варіант $\left(S, *_{a}\right)$ ізоморфний скінченній напівгрупі Брандта. То $S$ - скінченна иілком 0-проста напівргупа.

Доведення. Оскільки варіант $\left(S, *_{a}\right)$ ізоморфний напівгрупі Брандта. То за твердженням 4. напівгрупа $S \in 0$-простою. Оскільки $S \in$ скінченною та 0-простою, то за твердженням 2. напівгрупа є цілком 0-простою.

3 твердження 1. маємо, що якщо варіант $\left(S, *_{a}\right) \in 0$-простою, то $S \in 0$-простою. Тоді з твердження 3. напівгрупа $S \in$ цілком 0 -простою тоді і тільки тоді, коли $S$ не містить біциклічної напівгрупи.

Далі розглянемо варіант $\left(S, *_{a}\right)$ ізоморфний напівгрупі Брандта. Оскільки за твердженням 5. напівгрупа $S$ є скінченною цілком 0-простою.

То будемо розглядати більш загальний випадок, коли $S$ є цілком 0-простою.

Тоді за теоремою Pica 2. напівгрупа $S$ ізоморфна матричній напівгрупі Ріса над групою з нулем $\mathcal{M}^{0}\left(G^{0} ; I, J ; P\right)$. Тоді $\left(S, *_{a}\right) \cong\left(\mathcal{M}^{0}\left(G^{0} ; I, J ; P\right), *_{A_{i j}}\right)$ 
Твердження 6. Варіант напівгрупи $\mathcal{M}^{0}\left(G^{0} ; I, J ; P\right)$ породжений довільною не нульовою матрицею Рiса $A_{i j} \in$ рісівсъкою матричною напіргупою з сандвіч матрицею $Q=P A_{i j} P$.

Доведення. Розглянемо варіант $\left(\mathcal{M}^{0}\left(G^{0} ; I, J ; P\right), *_{A_{i j}}\right)$. Множення у цьому варіанті задано наступним чином, для довільних матриць Pica $X_{k l}, Y_{u v}$ маємо, що $X_{k l} *_{A_{i j}} Y_{u v}=X_{k l} \cdot A_{i j} \cdot Y_{u v}$, де $\cdot \epsilon$ множенням з напівгрупи $\mathcal{M}^{0}\left(G^{0} ; I, J ; P\right)$. Тоді $X_{k l} *_{A_{i j}} Y_{u v}=X_{k l} P A_{i j} P Y_{u v}=X_{k l}\left(P A_{i j} P\right) Y_{u v}$. Звідси бачимо, що $\left(\mathcal{M}^{0}\left(G^{0} ; I, J ; P\right), *_{A_{i j}}\right)$ $\epsilon$ матричною напівгрупою Ріса з сандвіч матрицею $Q=P A_{i j} P$.

З'ясуємо якого вигляду може набувати ця сандвіч матриця $Q$.

Твердження 7. Якщо у матриці $Q$ нуль стоїть на місиі $l k$, то нульовим буде або $k$-й стовпчик чи $l$-й рядок, або одночасно $k$-й стовпчик та $l$-й рядок.

Доведення. Нехай елемент $q_{l k}$ матриці $Q$ дорівнює нулю, тобто $p_{l i} e_{i j} p_{j k}=0$, тоді $p_{j k}=0$ або $p_{l i}=0$, або одночасно $p_{j k}=0$ та $p_{l i}=0$. У випадку $p_{j k}=0$ у матриці $Q$ нульовим буде весь $k$-й стовпчик. У випадку $p_{l i}=0$ у матриці $Q$ нульовим буде весь $l$-й рядок. Коли одночасно $p_{j k}=0$ та $p_{l i}=0$, то нульовими $\epsilon k$-й стовпчик та $l$-й рядок матриці $Q$.

Лема 1. [10, лема 3.1] Рісівсъка напівгрупа $\mathcal{M}^{0}\left(G^{0} ; I, J ; P\right)$ матричного типу з сенвіч матрицею $P$ над групою з нулем $G^{0}$ регулярна тодi $i$ тільки тодi, коли кожний рлдок i кожен стовпчик матриці $P$ містить не нульовий елемент.

Назвемо $I \times I^{\prime}$ матрицю $U$ над групою $G^{0}$ iнвертовною, якщо кожен рядок і кожен стовпчик матриці $U$ містить точно один не нульовий елемент напівгрупи $G^{0}$. Якщо $I \times I^{\prime}$ матриця інвертовна, то, очевидно, що $|I|=\left|I^{\prime}\right|$. Якщо $\omega-$ гомоморфізм групи з нулем $G^{0}$ в групу з нулем $\left(G^{\prime}\right)^{0}$ та $P=\left(p_{k l}\right)$ - довільна $J \times I$ матриця над $G^{0}$, то через $\omega(P)$ позначимо $J \times I$ матрицю $\left(\omega\left(p_{k l}\right)\right)_{k \in J, l \in I}$.

Наслідок 1. [10 лема 3.12]] Дві регулярні рісівсъкі напівгрупи матричного типу $\mathcal{M}(G ; I, J ; P)$ mа $\mathcal{M}\left(\left(G^{\prime}\right) ; I^{\prime}, J^{\prime} ; P^{\prime}\right)$ ізоморфні тоді і тільки тоді, коли існуе ізоморфізм $\omega$, який відображае $G^{0}$ на $\left(G^{\prime}\right)^{0}$, та такі інвертовні $I \times I^{\prime}$-матриця $U$ ma $J \times J^{\prime}$ матриия $V$, що $\omega(P)=V P^{\prime} U$.

Твердження 8. Жоден варіант $\left(\mathcal{M}^{0}\left(G^{0} ; I, J ; P\right), *_{A_{i j}}\right)$ матричної напівгрупи Ріса неізоморфний напівгрупі Piса з одиничною сендвіч матрицею $\mathcal{M}^{0}\left(\left(G^{\prime}\right)^{0} ; K, K ; \triangle\right)$.

Доведення. Зважаючи на твердженням 6. з'ясуємо чи ізоморфні напівгрупи

$$
\mathcal{M}^{0}\left(G^{0} ; I, J ; P A_{i j} P\right) \text { та } \mathcal{M}^{0}\left(\left(G^{\prime}\right)^{0} ; K, K ; \triangle\right) .
$$

Нехай $\mathcal{M}^{0}\left(G^{0} ; I, J ; P A_{i j} P\right) \cong \mathcal{M}^{0}\left(\left(G^{\prime}\right)^{0} ; K, K ; \triangle\right)$. Тоді існує ізоморфізм $\omega$, який відображає $G^{0}$ на $\left(G^{\prime}\right)^{0}$, та такі інвертовні $I \times K$-матриця $U$ та $J \times K$-матриця $V$, що $\omega(\triangle)=V Q U$. Тоді образом одиничної матриці $\triangle \epsilon$ матриця $V Q U$. Оскільки матриці $V$ та $U \in$ інвертовними то кожен рядок і стовпчик цих матриць містять точно один не нульовий елемент. Таким чином матриця $V Q U$ містить стільки ж не нульових елементів як матриця $Q$.

Оскільки $\omega\left(0_{i j}\right)=0_{i j}$ та $\triangle$ діагональна, то матриця $V Q U$ повинна бути діагональною і на діагоналі повинні стояти ненульові елементи. При множенні матриці $Q$ на $V$ та 
$U$ здійснюється множення рядків і стовпчиків матриці $Q$ на ненульові елементи та їх перестановка. 3 твердження 7. випливає, що матриця $Q=P A_{i j} P$ не може бути матрицею, що перестановкою рядків і стовпчиків зводиться до діагональної матриці. Оскільки якщо $Q$ містить нульовий елемент, то вона містить нульовий рядок чи стовпчик, а 3 доведеного вище $Q$ не повинна мати нульових рядків чи стовпчиків. Таким чином матриця $V Q U$ не $\epsilon$ діагональною матрицею.

Тоді наше припущення не вірне, тобто напівгрупи

$$
\mathcal{M}^{0}\left(G^{0} ; I, J ; P A_{i j} P\right) \text { та } \mathcal{M}^{0}\left(\left(G^{\prime}\right)^{0} ; K, K ; \triangle\right)
$$

неізоморфні.

Теорема 3. Нехай напівгрупа $S$ не містить біциклічної піднапівгрупи та $a \in S$, тодi $\left(S, *_{a}\right)$ не е напівгрупою Брандта.

Доведення. Нехай напівгрупа Брандта $B$ ізоморфна варіанту $\left(S, *_{a}\right)$ деякої напівгрупи $S$, та $a \in S$. Тоді за теоремою 1 . варіант $\left(S, *_{a}\right)$ є цілком 0-простою інверсною напівгрупою. 3 твердження 1. напівгрупа $S$ є 0 -простою.

Оскільки $S$ є 0-простою та не містить біциклічної піднапівгрупи, то з твердження 3. випливає, що $S$ є цілком 0-простою. Тоді за теоремою Ріса 2. напівгрупа $S$ ізоморфна матричній напівгрупі Рica $\mathcal{M}^{0}\left(G^{0} ; I, J ; P\right)$. Тобто

$$
\left(S, *_{a}\right) \cong\left(\mathcal{M}^{0}\left(G^{0} ; I, J ; P\right), *_{A_{i j}}\right) \cong\left(\mathcal{M}^{0}\left(G^{0} ; I, I ; Q\right)\right) .
$$

За твердженням 8. варіант $\left(\mathcal{M}^{0}\left(G^{0} ; I, J ; P\right), *_{A_{i j}}\right)$ неізоморфний рісівській напівгрупі матричного типу з одиничною матрицею $\mathcal{M}^{0}\left(G^{0} ; I, I ; \triangle\right)$.

Тобто варіант $\left(S, *_{a}\right)$ неізоморфний напівгрупі Брандта. Що і доводить теорему.

Наслідок 2. Скінченна напівгрупа Брандта не е варіантом жодної напівгрупи.

Доведення. Нехай скінченна напівгрупа Брандта є варіантом деякої напівгрупи $S$, очевидно, що це можливо тоді і тільки тоді, коли $S$ є скінченною. Оскільки скінченна напівгрупа не містить біциклічної підніпівгрупи, то з теореми 3. випливає, що жоден варіант $\left(S, *_{a}\right)$ не $є$ напівгрупою Брандта. Тобто скінченна напівгрупа Брандта не $є$ варіантом жодної напівгрупи.

Нехай $\mathfrak{B i}$ - біциклічна напівгрупа породжена елементами $a$ та $b$, тобто $\left\langle b^{l} a^{t} \mid a b=1\right\rangle$. Розглянемо варіант $\left(\mathfrak{B i}, *_{b^{m} a^{k}}\right)$.

Твердження 9. [13] Для кожного $\alpha \in \mathfrak{B i}, \alpha=b^{m} a^{k}$, множина ідемпотентів варіанmу $\left(\mathfrak{B i}, *_{\alpha}\right)$ мае вигляд $\left\{b^{k+i} a^{m+i}, i \geqslant 0\right\}$, причому ідемпотенти утворюють нескінченний спадний ланцюг відносно природного часткового порядку на множині ідемпотентів.

Твердження 10. Нехай напівгрупа $S$ містить піднапівгрупу $\mathfrak{B i}$, ma a $\in \mathfrak{B i}$. Тодi варіант $\left(S, *_{a}\right)$ не е напівгрупою Брандта.

Доведення. Маємо наступне включення для варіантів $\left(\mathfrak{B i}, *_{a}\right) \subset\left(S, *_{a}\right)$. За твердженням 9. варіант $\left(\mathfrak{B i}, *_{a}\right)$ містить нескінченний спадний ланцюг ідемпотентів, таким чином напівгрупа $\left(S, *_{a}\right)$ теж містить цей ланцюг. Тоді напівгрупа $\left(S, *_{a}\right)$ не містить примітивного ідемпотенту, тому не є цілком 0-простою. Тому з теореми 1 . випливає, що варіант $\left(S, *_{a}\right)$ не є напівгрупою Брандта. 


\section{Висновки}

3 доведених нами тверджень стає очевидним, що ключовим для позитивної чи негативної відповіді на запитання, чи є напівгрупа Брандта варіантомдеякої напівгрупи, $є$ наявність чи відсутність у даній напівгрупі біциклічної піднапівгрупи.

Ми довели, що варіант напівгрупи, яка не містить біциклічної піднапівгрупи та напівгрупи, яка містить біциклічну піднапівгрупу, варіант породжений елементом з цієї піднапівгрупи не є напівгрупою Брандта. Тож подальше дослідження слід сконцентрувати на дослідження напівгрупи, яка містить біциклічну піднапівгрупу і варіант породжений елементом не з біциклічної піднапівгрупи.

\section{Література}

[1] Ляпин Е.С. Полугруппы. - М.: Физматлит, 1960. - 592 с.

[2] Chase, K. Sandwich semigroups of binary relations // Discrete Math. - 1979. - V. 28(3). - P. 231-236.

[3] Hickey J. Semigroups under a sandwich operation. // Proc. Edinburg Math. Soc. (2) 1983. - V. 26(3). - P. 371-382.

[4] Khan T., Lawson M. Variants of regular semigroups. // Semigroup Forum. - 2001. - V. 62(3). - P. 358-374.

[5] Mazorchuk V., Tsyaputa G. Isolated subsemigroups in the variants of $\mathcal{Y}_{n}$. // Acta Math. Univ. Com. - 2008. - V. LXXVII 1. - P. 63-84.

[6] Dolinka I., East J. Variants of finite full transformation semigroups. // Internat. J. Algebra Comput. -2015. - 25(8) - P. 1187-1222.

[7] Desiateryk O., Ganyushkin O. Variants of a lattice of partitions of a countable set. // Algebra and Discrete Mathematics. - 2018. - V. 26 N.1 - P. 8-18.

[8] Magill K. D. Jr., Subbiah, S. Green's relations for regular elements of sandwich semigroups. I. General results. // Proc. London Math. Soc. - 1975. - 31(2) - P. 194-210.

[9] Ganyushkin O., Mazorchuk V. Classical Finite Transformation Semirgoups. An Introduction. - L.: Springer-Verlag, 2009. - 312 p.

[10] Clifford A.H, Preston G.B. The Algebraic Theory of Semigroups. - P.: American Mathematical Society. - 1977. - 224 p.

[11] Howie J.M. Fundamentals of Semigroup Theory. - NY.: Oxford University Press, 2003. $-354 \mathrm{p}$.

[12] Andersen O. Ein Bericht Ëuber die Struktur abstrakter Halbgruppen, PhD Thesis. - H.: 1952.

[13] Цяпута Г. Ю. Напівгрупи перетворень із деформованим множенням.// Вісн. Київ. ун-ту. Сер. фіз.-мат. науки. - 2003. - №3. - С. 82-88.

\section{Desiateryk O.O.}

junior researcher, Department of Neural Information Processing Technologies, International Research and Training Center for Information Technologies and Systems, National Academy of Sciences of Ukraine and Ministry of Education and Science of Ukraine (dissertation: Faculty of Mechanics and Mathematics, Taras Shevchenko National University of Kyiv)

\section{ON CONDITIONS FOR THE BRANDT SEMIGROUP TO BE NON-ISOMORPHIC TO THE VARIANT}

In this paper we study the question if the Brandt semigroup can be a variant of another semigroup or not. For a semigroup which does not contain a bicyclic subsemigroup we proved that a 
variant of such semigroup is not a Brandt semigroup. For an infinite semigroup which contains a bicyclic subsemigroup a variant with a sandwich element from this bicyclic subsemigroup is not a Brandt semigroup.

Key words: Brandt semigroup, variant, sandwich semigroup, bicyclic semigroup.

Десятерик А.А.

м.н.с., отдел нейросетевых технологий обработки информации, Международный научно-учебный центр информационных технологий и систем НАН Украины и МОН Украины (диссертачия: механико-математический факультет, Киевский Национальний Университет имени Тараса Шевченка)

\section{УСЛОВИЯ, ПРИ КОТОРЫХ ПОЛУГРУППА БРАНДТА НЕИЗОМОРФНАЯ ВАРИАНТУ}

В этой статье мы исследуем вопрос является ли полугруппа Брандта вариантом другой полугруппы. Мы доказали, что полугруппа, которая не содержит бициклическую подполугруппу не является полугруппой Брандта. Для безконечной полугруппы, которая содержит бициклическую подполугруппу, вариант порожденный елементом из этой подполугруппы не является полугруппой Брандта.

Ключевые слова: полугруппа Брандта, вариант, сандвич полугруппа, бициклическая полугруппа. 